\title{
Analyzing the cultural background of textile designers' on their innovative thinking
}

\author{
Dereje Debeli \\ Key Laboratory of Advanced Textile Materials and \\ Manufacturing Technology, Ministry of Education, \\ Zhejiang Sci-Tech University, Hangzhou, Zhejiang, \\ 310018, China \\ drjdebeli@gmail.com
}

\author{
Zhou Jiu* \\ Key Laboratory of Advanced Textile Materials and \\ Manufacturing Technology, Ministry of Education, \\ Zhejiang Sci-Tech University, Hangzhou, Zhejiang, \\ 310018, China \\ *Corresponding Author: zhoujiu34@126.com
}

\begin{abstract}
Textile design is a creative activity on textile materials and textile products by which textile designers put their personal emotions into a design process. These emotions and innovative ideas sourced from cultural background of designers such as different living environments, experiences, and formation of design styles itself is the subject matter. This paper introduces the significance of different cultural backgrounds, experiences of designers' innovative thinking from China, Africa and Muslim textile designers' case. These designers can fully grasp the differences between cultural values of the society and put forward their innovations through creativity by coupling those essences with an amazing design. As long as they take full advantage of cultural essence of diverse experiences, they have access to a successful conclusion.
\end{abstract}

Keyword - culture, innovation, textile design, fashion, designer

\section{INTRODUCTION}

Culture is used as an input for textile design in some circumstances. Designers use cultural essence to show moods, and styles in their innovations. Moods and styles are activities collected from a society and it's then presented artistically on patterns for textile decoration. These cultural values (that is moods, styles and other expression) can be learnt through an exposure to a given society for a certain period of time. Later, designers use this knowledge as back up to trigger their personal emotions in the design process [1], [2], [3]. One can recall that these values are unique in their ways of putting things together such as using colors, patterns, dressing styles and other related activities by citing culture as a reference.

The cultural routes provide a suitable strategy for the design process and also direct designers into the path of innovations by giving insightful information for contemporary arts and professional creativities. The concept of a particular design is always linked to given source such as religious, costumes or historical ruling classes. It was recently proved that this concept of culture as an alternative source for textile design holds, as, long as it provides designers necessary information [7], [8], [10].

Adopted culture is a brand originated from diverse African ethnic fabrics. It stands for embracing different cultural values, styles and originalities through fashion. Known traditional patterns and fabrics such as kente, adire, adinkira and raffia of Congo are main inputs of this collection. Mao's new suit, Sun Yat sen suit and many cheongsam dress based brands are also primary cultural inputs in China. Thus, contemporary Chinese designers have been incorporating these historically rich textile sources to reflect aspects of the past as well as embracing new hopes in the future. Similarly, Tiraz, "Islamic embroidery", is the bases for Jilbabs, hijabs and galabiyyas luxury brands of today's Muslim artistic expressions, ideas and styles of the society. These contemporary designs have brought social arts, expressions and political changes to wearable fashion pieces, across their culture.

This paper introduces the impact of culture on innovation in the case of textile design. It analyses the diverse cultural input from textile designers' experiences throughout Africa, china, Japan and Muslim societies. Sources from which design ideas are taken such as culture, environment and religious are very important for the whole design process. However, by considering culture as determinant factor and inclusive of all, in nourishing designers' imagination, for creating luxury brands are given cases for discussion. This case study gives an overview of successful designers overwhelmed by cultures later used as an input over other designers for their innovations.

\section{CULTURE AS AN ELEMENT OF INNOVATIONS}

If one designer is born in a given society and raised up in same environment, it is must to understand all expressions, culture and values of that specified area. Moreover, advancing his basic knowledge with activities such as travelling and staying outside of his society brings him another way to experience different styles, cultures and customs. Up on exposure to this new culture, new areas will direct him to think and compare dressing styles. This finally inspires him to improve shapes through his cultural style, or adopting the style to his society. This source of inspiration, ideas might be it in terms of colors selection, choosing styles, patterns or anything that step up the designer from one working procedures to another. Such experience of different cultures, expressions and values are direct inputs for a designer.

Elements such as bold hues, powerful patterns, and brightness and fashion styles are culturally determined components of textile design. The joy of life, colors, has 
important meaning in a society. The meaning gets different along different cultures. For instant, in some African countries Red represents for political, power and strength, and in China red color stands for luckiness, happiness and used for festival activities whiles the same color in Japan stand for indicating danger or anger. Colors are pronounced as to become bold in African textile materials. It can be achieved either through controlling the brightness or equally use deep hues. Arts on a pattern have their own meaning. Its meaning and representation is also varying as we go from one culture to another.

\section{HOW DESIGNER'S BACKGROUNDS AFFECT INNOVATIVE THINKING?}

Designers are in the era of giving emphasis to give priority for ethnic diversity based innovations. Because every culture has something unique to offer for the present day fashion trends, most western markets are evident in these trends [9]. Art is a product of human mind that transmit emotions or ideas upon exposure to ordinary changes. This transmission inspires designer for generating ideas, new concepts that can bring him for collecting information. That means, observing the status of culture or collecting necessary information will let him come up with upcoming fashion trends. Textile products can reflect level of development and other cultural values in a society in terms of arts. So, designers sometimes plan to convey those cultural values through arts by adding spices to their creative design works. The valuing of aesthetics, color preferences, type of patterns and style included in decoration are much more than the science of fashion. For a designer, these essences are everything. By shaping or slightly changing or adding their own styles, they make presentable for their collection. A brand name "Adopt culture" can be taken for instant; it reflects the rich African traditional dressing background for its foundation. It has brought different cultural trends across Africa to a unified design. This brand is come to be known with its beautiful design elements combination (positively vibe) that is a funky twist of multi-cultural decoration styles. It brings cultural based innovation styles to the fashion industry.

Therefore, patterns and styles developed can also be benchmarked from already known steps. Following the steps; drawing, cutting, or redoing might be required until they become familiar to that system. Textile designers and artists who are known for their cultural focused brand reputation throughout different cultures are studied and presented in the following cases. For this particular study, Chinese, African, Japanese and Muslim cultures are given cases to be discussed for illustration purpose.

\section{A. Cases 1}

Nana Afua Antwi is a high profile contemporary African designer, the top color model and the founder and creator of adopted cultural fashion brand. What makes her unique is that she used different cultural styles and values in her design works by saying adopted culture. She had basic cultural knowledge which helped her to analyze some African dressing styles. Then, she collected cultural fabrics made of African patterns from ethnic groups to combine them accordingly. Using local motifs (mainly using Kente, Adire, Adinkira and Raffia), following African design principle, from known geometric structure, by following deep color preferences, and reputation of strip line across the pattern via big size of elements on design, she made western style, shape of garment. Presenting African textile products, with African color selection but borrowing western style draws her to win the 2011award [7], [8], and [10]. On her works, she developed real African prints with different color choices, in multiple styles for international design reputation. This made her known to be one of the top fashion designers and color model in UK with her creative styles from rich African cultural background. Her African and European cultural knowledge also contributed her to be a successful, creative over the other designer to exhibit and sells her products in most western markets.

In the same ways most African designers do follow the same system to develop different products from locally available patterns. This basic knowledge and cultural domination will influence them on concept development, production process and help them up to the product development as illustrated by figure1 shown below.

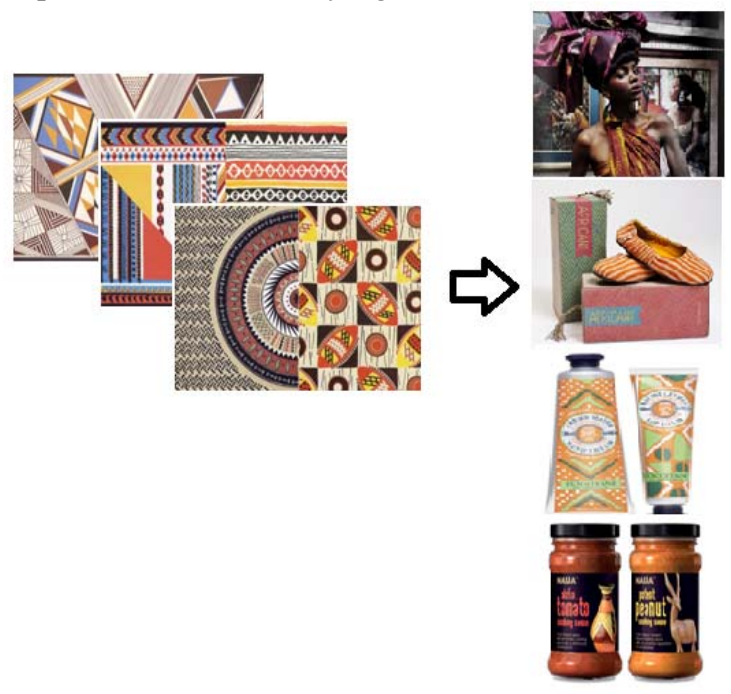

Figure 1 Example of African pattern and its cultural values

\section{B. Case 2}

The Islamic culture has contributed insightful styles for textile design and fashion industries since a long time by shaping Muslim dressing costume. That means every day to day activities including textile designs and arts have been regulated by this Islamic culture. These, Islamic textiles and arts are always decorated with multi layered patterns for both females and men by shows their devotion to God. So, the styles and dressing have been shaped by the religious considering the climate, cultural aesthetics, trade patterns, economics and political situation. Of course, without this 
information we might get difficulty to know what types of materials are allowed or which are not allowed for these fabrics construction. For example, Rayannes Design, international brand name, set out to create fashion for Muslim that was simple, stylish and comfortable. She understood and took into account the everyday needs of a Muslim woman who needed to dress modestly, played key roles in society [5], [6], and [12]. Such designs offer Muslim Women the freedom to dress modestly in accordance with the latest trends available in the international market without violating their religious wearing style. Similarly, other designers also get design concepts from a pattern called "Tiraz" which was traditionally preferred for religious services. Referring this service, most local designers use the original style and develop into luxury fashion brands.

\section{Case 3}

As in many cultures, dress was a way of distinguishing a person's position in Chinese society. The "Cheungsam" is regarded by many as the classic national dress for women originated from the Qing dynasty, the Mao suit which reflects the political change from recent years. Contemporary designers came out referring this culture as their sources for creativity in the design industry. For instance, Sun Jian was a famous Chinese designer in 1990s. On her elegant and classical design collections, she had developed a carefully mixed western style with traditional Chinese dress inspired by cheungsam and Mao suit [9]. Sun Yatsen-style jackets, and qipao, cheongsam-style evening dresses are famous brands.

Furthermore, most Chinese designers are seen using pattern derived from dragon. Dragon is a powerful pattern for design art works in Chinese context. This dragon based powerful patterns are used as source for many designers to produce textile products. Textile application has reached at high level; so cultural patterns along its applications for contemporary fashion are also seen through Chinese designers' creativity in most cases. So, this concept is more evident as more people on designing field are preferred to use dragon pattern-derivative design arts for different product diversities, as illustrated by figure 2 .
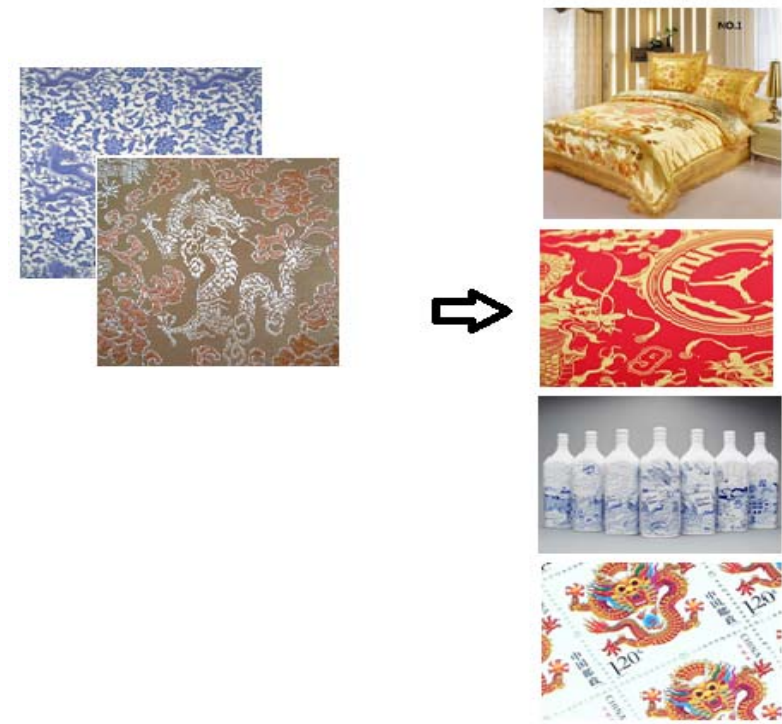

Figure 2 Example of Chinese dragon pattern and its application

\section{Case 4}

Akira Isogowa is one of the top famous designers recently in Australia. In fact, he was born and raised in Japan, then migrate to Australia. He started doing fashion using the fabric he knew based on traditional Japanese costume from kamino. The patterns were the same, square piece of cloth made into sleeve and then to produce cloth, the so called fashion. According to Akira's, first he understood the traditional Japanese custom design, then through evolution he leant the western designing styles; by cutting, sewing and pressing them to the desired fashion [11]. His works have been reflected a lot about his inspiration that he got from Japanese traditional design and childhood experiences which finally drove him to design for his present day contemporary fashion. So, his home town, Australian knowledge and experience enabled him amazingly to exploit the Paris market.

To sum up, designers have regional, cultural, and environmental based influences from a certain social groups, these effects later do have an impact on their creative thinking. Popular activities in a society such as dancing, pop cultures are followed and understood by lager groups. This type of culture in terms of textile design is the culture that influences our daily lifestyle and determines our looks, dresses. This is the very important information for designers to look and copy their moods and emotions that what those groups like to dress; or by keeping an existing model and modify a little style as per requirements for the living fashion industries. Generally, to understand textile design and fashion trends, we need to be aware of the surrounding in terms of our social, cultural and environmental way of living style in a specified time. 


\section{CONCLUSION}

Textile design is a creative activity by designers across different cultures of Africa, China, Japan or multi-cultural societies. This cultural focused innovation designs are getting into the societies' to show many moods, and styles. Designers cultivated in such a diverse culture can better demonstrate their feelings and emotions from a society and reflect back to them through their design works. This cultural influence can also enrich their innovative thinking toward designing cultural patterns out of them.

These diverse societies besides their cultures have been used as main input for textile design products since long time. In addition to the formal use, it has also used as medium of communication between community and designers by providing necessary information on how they feel and what they look. Each culture has unique elements to share for the present fashion trends which maybe in hidden or transmittable kind of symbols that are mostly embedded in a form of textile arts. It is this knowledge that ignites creativity as background information. This type of cultural backup is very crucial in the first stage of product design process. This knowledge is partly used as instinctive cultural preference value over the learnt one. Finally, it is much important to notice that culturally attentive designers are required to sense user's needs and wants. So this research provides grounds for textile and fashion designers to be further attentive in the field of cultural background knowledge. Thus, as designers make efforts in mastering others cultures beside their native, increase their experiences in the global textile product development.

\section{ACKNOWLEDGEMENT}

This research was funded in part through a grant of the National Social Science Fund Art Project (12BG064) and Zhejiang New century Education Reform Project (YB2010024).

\section{REFERENCES}

[1] Shin, M.J. Cassidy, T. and Moore, E.M Cultural Reinvention: design marketing for cultural Textile products

[2] Mohammad Razzaghi, Cultural patterns in product design Ideas: Comparisons between Australian and Iranian Student concepts, 2008

[3] Diana Crane, Laura Bovone, Approaches to material Culture: The sociology of fashion and clothing 1, November 2006

[4] Ashley Mears Size zero high-end ethnic: Cultural Production and the reproduction of culture in fashion Modeling

[5] Religious, Spiritual, Pastoral \& Cultural care A guide for staff in providing good Religious, Spiritual, Pastoral \& Cultural Care

[6] Maggie Asplet, Malcolm Cooper, Cultural designs in New Zealand souvenir clothing: The question of Authenticity, February 1999

[7] The promotion and protection of Africa's cultural Products, advocacy statement, 2006

[8] Jean Marie Allman Fashioning Africa Power and The Politics of Dress (African Expressive Cultures, (2004)

[9] Yao Zeng, Chinese influence on western women's dress In American vogue magazine, December 2011

[10] Ciaafrique African fashion week, Designer Nana Afua Antwi, Sunday, May 15, 2011
[11] Project overview Exhibition presented at the Powerhouse Museum, Sydney 12 April - 21 July, 2002)

[12]http://www.ciaafrique.com/2011/05/designer-spotlight-adoptedculture-by.html 